\title{
A Comparison of Type II Diabetic Patients With Healthy People: Coping Strategies, Hardiness, and Occupational Life Quality
}

\author{
Safdar Karimi, ${ }^{1}$ Asghar Jaafari, ${ }^{1}$ Mohammad Ghamari, ${ }^{1}$ Maryam Esfandiary, ${ }^{2}$ Foroozan \\ Salehi Mazandarani, ${ }^{3}$ Sahar Daneshvar, ${ }^{4}$ and Marjan Ajami ${ }^{5,}$ \\ ${ }_{2}^{1}$ Abhar Branch, Islamic Azad University, Abhar, IR Iran \\ ${ }^{2}$ Roudhen Branch, Islamic Azad University, Roudhen, IR Iran \\ ${ }^{3}$ Health Deputy, Ministry of Health and Medical Education, Tehran, IR Iran \\ ${ }_{5}^{4}$ Faculty of Physical Education and Sports Sciences, Tehran University, Tehran, IR Iran \\ 5 Fepartment of Food and Nutrition Policy and Planning Research, Faculty of Nutrition and Food Technology, National Nutrition and Food Technology Research Institute, Shahid \\ Department of Food and Nutrition Policy and Plannin
Beheshti University of Medical Sciences, Tehran, IR Iran \\ *Corresponding author: Marjan Ajami, Department of Food and Nutrition Policy and Planning Research, Faculty of Nutrition and Food Technology, National Nutrition and Food \\ Technology Research Institute, Shahid Beheshti University of Medical Sciences, Tehran, IR Iran. Tel: +98-9126719294; +98-2188577364, Fax: +98-2188675760, +98-2188675760, E-mail: \\ nutritionist80@gmail.com
}

Received 2014 September 30; Revised 2015 March 10; Accepted 2015 April 2.

\begin{abstract}
Background: Due to the epidemiologic transition and a rise in the prevalence of non-communicable diseases different coping strategies have been studied and developed. These strategies may help the affected people to conduct a normal life style.

Objectives: This research was conducted in Qazvin, Iran to determine the relationship between coping strategies, hardiness, and occupational life quality in Type II diabetic patients and healthy people.

Patients and Methods: Questionnaires such as Valton's on “occupational life quality," Billings and Moos' examination of "Coping strategies," and Kobasa's investigation of "hardiness" were applied to collect the data needed for the present study. In this regard, 80 people were randomly selected from employees of offices in Qazvin, Iran.

Results: The results of this research indicated that there is a significant relationship between problem-focused strategies, emotionfocused strategies, hardiness, and occupational life quality in people suffering from Type II diabetes and healthy people $(\mathrm{P} \leq 0.05)$. These results also indicated that hardiness does not predict occupational life quality of people suffering from Type II diabetes.

Conclusions: The results of the present study give some evidence that allows us to conclude that hardiness and coping strategies affect occupational life quality for both people suffering from Type II diabetes and healthy people. Therefore, it is proposed that people strengthen their hardiness and coping strategies, in order to improve their occupational life quality.
\end{abstract}

Keywords: Coping Skills, Occupational, Quality of Life, Diabetes Mellitus

\section{Background}

Many epidemiologic, nutritional, and demographic transitions occurred in the twentieth century. Promoting the components of a healthy lifestyle and improvements in many countries' social and economical conditions over the past several centuries have brought about the reduction, control, and elimination of many fatal infectious diseases. On the other hand, due to changes in lifestyle and industrial advances, chronic and non-contagious diseases have become a serious threat to human health. Nowadays, there are four main groups of non-contagious illnesses: cardiovascular diseases, cancers, chronic respiratory diseases, and diabetes, all of which are known to be the most important threats to human life and abilities. Their side effects can impose heavy pressure on families, societies, and governments (1).

Suffering from diabetes disease, and the obligation of the patient to take special care of him or herself, can cause many challenges in diabetics' life routines, as they cope with these challenges. Consequently, they need to adopt proper coping strategies. Coping strategies can play an important role in the disease control, therapy, and psychological-social adaptation of diabetes patients (2).

Strategies for coping with diabetes have been subject to many discussions. Some researchers have claimed that problem-focused strategies can successfully increase self-caring abilities in diabetic patients, while motion-focused methods can have harmful effects. Therefore, a wide range of coping behaviors, including problem-focused and motion-focused coping strategies, have been recognized for their ability to decrease stresses related to the disease. Studies have indicated that dia-

Copyright (C) 2016, Zahedan University of Medical Sciences. This is an open-access article distributed under the terms of the Creative Commons Attribution-NonCommercial 4.0 International License (http://creativecommons.org/licenses/by-nc/4.0/) which permits copy and redistribute the material just in noncommercial usages, provided the original work is properly cited. 
betes disease can have a negative effect on physical function, increasing psychological and spiritual side effects, and personal, family, and social communication (3).

Psychological hardiness is a very important and prominent character feature that plays an important role in recognizing humans as free and valuable beings. This feature introduces the notion of humans as efficient and powerful creatures that, even in the most critical conditions and situations under a lot of pressure, can apply logical and rational coping strategies while also protecting his body and mind (4).

Hardiness is one of the beliefs in the basic role of the quality of human life. It is responsible for establishing equilibrium among the various dimensions of life.

Humans' belief systems often cause improvements in behavior, increase healthiness, life satisfaction, and life quality promotion; on the other hand, it seems that many problems and issues that people face with in their lives and experiences are as a result of these beliefs. People's system of belief have a wide effect on the establishment of equilibrium among the various dimensions of life, and as guides for patterns of behavior, they enable humans to expand the desirable consequences and avoid the unwanted consequences of their actions (5).

Many studies have investigated hardiness and its effects on human health and chronic disease. Baron indicated in his report that people with high levels of hardiness usually behave more effectively and constructively against the pressures and difficulties that commonly occur in workplace environment, and they rarely allow such pressures to continue and lead to physiological disease. There exists strong evidence indicating that hardiness has a positive correlation with physical and mental health (4).

The quality of professional life refers to applying conscious efforts to create a high quality professional life, so that these regular efforts are organized by an organization that gives greater opportunities to its workers in order to have a positive effect on their work $(6,7)$.

In recent years, programs designed to improve the quality of professional life have had a fundamental and important role in increasing the efficiency of human resources; consequently, they have been responsible for the effectiveness and efficiency of well-respected organizations and companies. Strategic programs of promoting the quality of workers' professional lives within organizations is a wide approach, indicating that cultivating an efficient human workforce plays an important role in the evolution of organizations. In modern societies, the promotion of professional life quality is a comprehensive program designed to attract the attention of workers and to help them manage changes, all while preserving workers inside the organization. Dissatisfaction with professional life and low professional life quality are fundamental problems that can affect all workers' lives, regardless of their position and rank, and may endanger individuals' mental and physical health by imposing stress and other disturbing factors upon them $(8,9)$.

Many studies have indicated that there is a significant relationship between professional life quality, job control, occupational stress, and the frequency and intensity of physical disease. In addition, many studies' findings indicate a significant and positive association between the extent of occupational stress and physical diseases. However, a negative significant relationship is reported between professional life quality and occupational stress, and between job control and occupational stress. Also, a negative significant relationship has been reported between professional life quality and physical disease, and job control and physical disease (10).

\section{Objectives}

Since no research to date has been conducted on the relationship between professional life quality and coping strategies, along with hardiness, in diabetes patients, this paper aims to respond this question that "Do coping strategies (problem-focused and motion-focused) and hardiness explain professional life quality of patients with Type II diabetes and healthy people?"

\section{Patients and Methods}

This study employs an applied research style. The relationship between the variables of coping strategies, along with hardiness as a predictor variable and professional life quality as the dependent variable, is investigated. For analysis apart from data descriptions, the Pearson correlation coefficient and multiple regression analysis are used. Before executing the main regression analysis for each specific question, a complete regression analysis model was executed for the variable of professional life quality, considering hardiness and all coping components. This analysis was executed with two purposes in mind: The first purpose is to investigate the basic hypotheses of multiple regression analysis, such as the linearity of the relationship between the target variable and predictor variables, normality and homogeneity of dispersion of conditional distributions. Although the $\mathrm{F}$ test used for $\mathrm{R}^{2}$-significance is resistant to the mean deviation of some of these hypotheses in regression analysis, hypotheses such as the non-linearity of the relationship, the estimation accuracy of parameters, and resulting interpretations are effective. Furthermore, to complete the first purpose, some separate regressions of professional life quality were executed individually on scales, to cause situations of data distribution to be investigated accurately. The second purpose of this analysis was to investigate the success value of the general model in predicting variables of professional life quality and determining the value of $\mathrm{R}^{2}$.

This study was carried out between April and June 2013. Our research sample included 40 people of both genders (20 men, 20 women) suffering from diabetes and rang- 
ing in age between 24 and 60 years old (45.1 \pm 10.7 years). They were selected by a simple random sampling method from among the staff of governmental organizations in Qazwin, Iran. A non-diabetic group (healthy people) consisted of 40 people who were same age range (mean age $44.3 \pm 11.2$ years old) and gender distribution, and from same professional organizations as members of the diabetic group. The majority of the participants had education of more than 12 years old.

Instruments of this research were Walton's professional life quality questionnaire (11), of Billings and Moos' (1981) Questionnaire of coping strategies (12), and Kobasa's hardiness questionnaire (13).

In this research, Walton's (11) questionnaire was used to evaluate the professional life quality of school managers. The instrument consists of eight indices of professional life quality. The questionnaire employs a 5-degree Likert scale, and its variations ranges from "very low" to "very high." Psychometric experts verified the format and content validity of all questions. The reliability of this questionnaire is reported as $\alpha=0.89$ by Pardakhtchi et al. (14), and the reliability obtained in this research was based on Cronbach's alpha of 0.87 .

A study by Khaghani and colleagues investigated the relationship between occupational stress and the professional life quality of nurses employed in selected armed forces hospitals. To evaluate the validity of their professional life quality questionnaire, they used a formal method and, in order to determine reliability, they used the retest method. The correlation coefficient calculated by these methods was equal to 0.9 , which indicates an appropriate correlation of questions $(15,16)$. Primary studies were implemented to determine the validity and reliability of the professional life quality questionnaire; Cronbach's alpha was reported as 0.95 (17).

Billings and Moos' (1981) Questionnaire of Coping Strategies consists of 19 terms that consider two coping strategies: problem-focused coping strategies (11 terms), and emotion-focused coping strategies (8 terms). The subject should sign any term that is counted as a type of coping response based on the extent to which he or she uses that method on a four-choice Likert scale (Never $=0$, sometimes $=1$, often $=2$, always $=3$ ). In Iran, Barahini and Mousavi used a four-choice Likert scale ranging from 0 to 3 , instead of a "yes or no" format. They declared an internal consistency range from 0.41 to 0.66 (14).

Kobasa's 1976 hardiness questionnaire consists of 50 provisions in which subjects should determine the correctness and incorrectness levels of sentences using a four-choice scale. This test consists of components related to challenge, commitment, and control, and each has 17,16 , and 17 provisions, respectively. Due to previous studies conducted in our country, the validity of the hardiness scale is supported. For instance, Kiamarsi and Abolghasemi (18) reported validity as Cronbach's alpha of hardiness scale, and subscales of commitment, control, and challenging at $0.86,0.83,0.72$, and 0.69 , respec- tively. In a primary investigation of a Persian form of the hardiness scale, psychometric indexes of three samples of students, athletes, and patients were reported. Alpha coefficients ranged from 0.88 to 0.93 for the commitment subscale, from 0.85 to 0.94 for the control subscale, from 0.89 to 0.95 for the challenge subscale, and from 0.87 to 0.94 for the total hardiness score, which indicated an appropriate internal consistency of scale (19, $20)$. As the study was observational and the data were kept confidential, there seem to be no ethical conflicts associated with the study.

\section{Results}

To respond the research question "Is there a significant correlation between professional life quality and coping strategies (problem-focused and emotion-focused strategies), and hardiness specifically?" a correlation matrix is used to shows two-by-two correlations between variables, as shown in Table 1 .

The relationship between the variables of problemfocused strategy and professional life quality is significant $(\mathrm{r}=0.345, \mathrm{P}<0.001)$. Since the value of this ratio is positive, it indicates that there is a positive relationship between the variable of problem-focused strategy and variable of professional life quality. This means that the more a person uses problem-focused strategies, the greater is his or her professional life quality. Correlation coefficients between professional life quality along with applying emotion strategies (-0.009) and hardiness (-0.102) are statistically not significant. The relationship between hardiness is not significant with any of these variables.

A multiple regression model was applied to investigate the main question of the research "Are coping strategies (problem-focused and emotion-focused), and hardiness able to explain professional life quality among Type II diabetic people and healthy people?", and also to determine the portion of each of them in predicting professional life quality (Table 2). According to the matrix of correlation of predictors with each other and with target variable, which is shown in Table 1, all correlation ratios among predictor variables were less than 0.9 , hence the probability of colinearity is low among predictor variables.

Finally, these variables explain $11.2 \%$ of the variance among the target variable (professional life quality) in patients suffering from Type II diabetes and among healthy people (Table 3). Also, the results of the F test verify the significant relationship of the $\mathrm{R}^{2}$ (Determination ratio). Finally, the table values verify the determinant ratios of problem-focused coping strategies with values of $\mathrm{t}=3.468, \mathrm{P}=0.001$, and $\beta=0.38$ (Table 4 ). Beta values related to problem-focused coping strategies indicate that, if one unit is added to problem-focused coping strategies, the professional life quality of both Type II diabetic people and healthy people will increase up to $38 \%$. 
Karimi S et al.

\begin{tabular}{|c|c|c|c|c|}
\hline Variables & Professional Life Quality & Hardiness & $\begin{array}{l}\text { Problem-Focused } \\
\text { Coping Strategy }\end{array}$ & $\begin{array}{c}\text { Emotion-Focused } \\
\text { Coping Strategy }\end{array}$ \\
\hline \multicolumn{5}{|l|}{ Professional life quality } \\
\hline Correlation coefficient & 1 & 0.102 & $0.345^{\mathrm{a}}$ & -0.009 \\
\hline Pvalue & NA & 0.271 & 0.002 & 0.672 \\
\hline \multicolumn{5}{|l|}{ Hardiness } \\
\hline Correlation coefficient & -0.102 & 1 & 0.113 & 0.121 \\
\hline Pvalue & 0.271 & NA & 0.273 & 0.311 \\
\hline \multicolumn{5}{|l|}{ Problem-focused strategy } \\
\hline Correlation ratio & $0.345^{\mathrm{a}}$ & 0.113 & 1 & $0.240^{\mathrm{a}}$ \\
\hline Pvalue & 0.002 & 0.273 & NA & 0.031 \\
\hline \multicolumn{5}{|l|}{ Emotion-focused strategy } \\
\hline Correlation ratio & -0.009 & 0.121 & $0.240^{\mathrm{a}}$ & 1 \\
\hline Pvalue & 0.672 & 0.311 & 0.031 & NA \\
\hline
\end{tabular}

Abbreviation: NA, not available.

$\mathrm{a}_{\text {Stasistically differences. }}$

Table 2. Summary of Regression Model Simultaneous With Professional Life Quality, in Terms of Predictor Variables

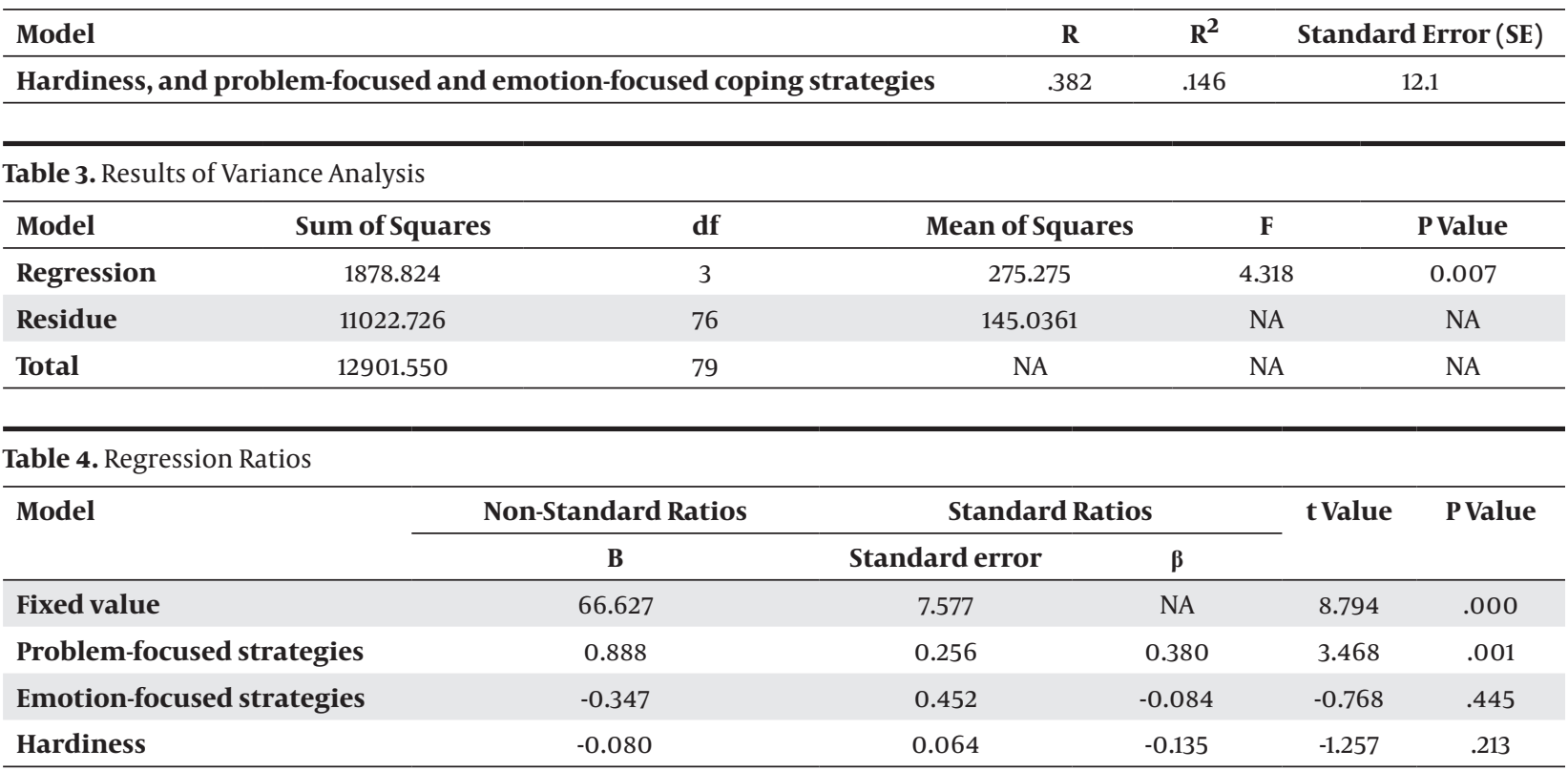

Abbreviation: NA, not available.

\section{Discussion}

According to the research findings, we conclude that coping strategies (problem-focused and emotion-focused) and hardiness can explain the professional life quality of people suffering from Type II diabetes and for healthy people. This finding is in accordance with findings of Besharat et al. and Bayrami and Esmaili (21, 22).

According to the model by Folkman and Lazarus (24) cognition strategies are used to solve the problem. In other words, problem-focused efforts include the execution of direct activities to change stressful situations and to prevent or reduce their effects. People apply problem-focused coping strategies when they believe that they will work the face of a stressful situation. Emotionfocused coping strategies are meant to eliminate the emotional effects of stressful factors. Emotion-focused efforts are concentrated on changing emotional reactions of pressure-making factors. The personality trait of hardiness creates a specific internal approach that influences peoples' confrontation methods when faced with various problems. This trait also causes people to con- 
sider stressors realistically and wisely. Hardiness is due to knowledge based on the fact that people with accesses to more resources can respond better to stressors. In other words, hardiness is a basic feeling of control that enables a tough person to draw on and have access to a list of useful strategies that he or she can afford. Consequently, hardiness leads to the establishment of an optimistic view about stressors $(4,23)$. Hardiness is a set of personality traits that acts as a source of resistance against life's pressures. Cognition strategies are used to solve problems. Accordingly, various coping strategies for problems are directly investigated, so that they include all potential abilities of person to allow positive coping with the problem and the solving of it, usually by finding suitable solutions. Psychological satisfaction is the common result. Therefore, efficient coping methods, such as increasing people's self-confidence, improve their problem solving skills and leads to more satisfaction (23).

In the present study, we determined that none of the variables of hardiness and emotion-focused coping strategies have an effect on the professional life quality of diabetic people, since emotion-focused strategies are meant to eliminate the emotional reactions to stressful factors. Emotion-focused efforts are dedicated to changing emotional reactions into pressure-making factors. A diabetic person requires both physical and mental adjustment and should have a new view of him or herself. Chronic and routine stresses have important effects on physical and psychological disturbances, and Type II diabetes is very sensitive to the effects of stress (24-26).

Both variables of hardiness and problem-focused strategies have an effect on the professional life quality of healthy people. Accordingly, various coping strategies are directly investigated, so that they include all potential abilities of a person to engage in positive coping and to solve problems, usually by finding suitable solutions. Psychological satisfaction is the common result. Therefore, efficient coping methods such as increasing people's self-confidence improves their problem solving skills and leads to greater satisfaction $(27,28)$.

On the other hand, some studies have indicated that the hardier people are, the less they evaluate stressful conditions as threatening, and they take advantage of effective coping strategies. When people do not have the ability to control themselves emotionally, have less incentive to try and remain stable when faced with routine stresses, and since they have a low attempt and stability, they cannot easily solve their problems. This causes increases their levels of routine stresses. However, it should be noted that, in some situations, a person is not able to control his or her negative emotions, so methods and strategies for coping with emotions can be useful compared to not applying these strategies (29-31).

According to the positive relationship between problem-focused strategies and professional life quality, it seems that holding training classes about applying problem-focused coping strategies and giving self-confidence to participants would have a positive and appropriate result in promoting the psychological health of employees and, consequently, in increasing their efficiency. Planning to train managers about coping strategies, hardiness, and professional life quality is imperative, so that effective strategies for improving occupational conditions and decreasing occupational stress of employees can be compiled in ways such as increased employee participation in decision-making, increased employee support, and a decrease in employee workloads $(28,32-35)$

The main limitation of our study is its small sample size.

\section{Acknowledgments}

We thank all subjects who participated in this study.

\section{Footnote}

Authors' Contribution:Safdar Karimi, Asghar Jaafari, Mohammad Ghamari, and Maryam Esfandiary have designed and conducted the research. They and Foroozan Salehi Mazandarani, Sahar Daneshvar, and Marjan Ajami have contributed to the analysis of the data and general design of the manuscript. Marjan Ajami has drafted the manuscript. All authors have read the manuscript and approved it.

\section{References}

1. Mokdad AH, Ford ES, Bowman BA, Nelson DE, Engelgau MM, Vinicor F, et al. Diabetes trends in the U.S.: 1990-1998. Diabetes Care. 2000;23(9):1278-83. [PubMed:10977060]

2. Gafvels C, Wandell PE. Coping strategies in men and women with type 2 diabetes in Swedish primary care. Diabetes Res Clin Pract. 2006;71(3):280-9. doi: 10.1016/j.diabres.2005.07.001. [PubMed: $16242806]$

3. Lustman PJ, Anderson RJ, Freedland KE, de Groot M, Carney RM, Clouse RE. Depression and poor glycemic control: a meta-analytic review of the literature. Diabetes Care. 2000;23(7):934-42. [PubMed:10895843]

4. Kobasa SC. Stressful life events, personality, and health: an inquiry into hardiness. J Pers Soc Psychol. 1979;37(1):1-11. [PubMed: 458548]

5. Caprara GV, Barbaranelli C, Pastorelli C, Bandura A, Zimbardo PG. Prosocial foundations of children's academic achievement. Psychol Sci. 2000;11(4):302-6. [PubMed:11273389]

6. Bar-On R, Tranel D, Denburg NL, Bechara A. Exploring the neurological substrate of emotional and social intelligence. Brain. 2003;126(Pt 8):1790-800. doi:10.1093/brain/awg177. [PubMed:12805102]

7. Grey M, Boland EA, Davidson M, Li J, Tamborlane WV. Coping skills training for youth with diabetes mellitus has long-lasting effects on metabolic control and quality of life. J Pediatr. 2000;137(1):107-13. doi: 10.1067/mpd.2000.106568. [PubMed: 10891831]

8. Landsbergis PA. Occupational stress among health care workers: A test of the job demands-control model. J Organiz Behav. 1988;9(3):217-39. doi: 10.1002/job.4030090303.

9. van der Klink JJ, Blonk RW, Schene AH, van Dijk FJ. The benefits of interventions for work-related stress. Am J Public Health. 2001;91(2):270-6. [PubMed:11211637]

10. Shapiro SL, Astin JA, Bishop SR, Cordova M. Mindfulness-Based Stress Reduction for Health Care Professionals: Results From a Randomized Trial. Int J Stress Manag. 2005;12(2):164-76. doi: 10.1037/1072-5245.12.2.164.

11. Walton RE. Criteria for Quality of Working Life. In: Davis LE, Cherns AB, editors. The Quality of Working. New York: The Free Press; 1975. pp. 91-104.

12. Billings AG, Moos RH. The role of coping responses and social resources in attenuating the stress of life events. J Behav Med. 
1981;4(2):139-57. [PubMed:7321033]

13. Kobasa SC, Maddi SR, Kahn S. Hardiness and health: a prospec tive study.J Pers Soc Psychol. 1982;42(1):168-77. [PubMed:7057354]

14. Pardakhtchi MH, Ahmadi GA, Arezoumand F. The quality of work life and burnout among teachers and principals in Takestan Schools. J Educ Leadersh Administrat. 2009;3(9):25-50.

15. Khaghani Zadeh M, Ebadi A, Sirati Nir M, Rahmani M. Relationship between job stress and quality of life of nurses inhospitals armed forces. Mil Med J. 2008;10(3):175-83.

16. Najimi A, Goudarzi AM, Sharifirad G. Causes of job stress in nurses: A cross-sectional study. Iran J Nurs Midwifery Res. 2012;17(4):3015. [PubMed: 23833631]

17. Yavari Y, Amirtash AM, Tondnevis F. Comparison of quality of work life among faculty members in physical education faculties and departments. J Movement Sci. 2009;15(5):168-79.

18. Kiamarsi A, Abolghasemi A. The Relationship of Self-Efficacy, Sensation Seeking and Coping Sterategies with Aptitude of Substance Use in University Students. Res Addict. 2012;5(20):17-24.

19. Barahini M. Assessment of reliability and validity of the Eysenck Personality Questionnaire; Seminar on Psychology and Psychiatry; Tehran. 1993.

20. Nabiei A, Karamafrooz MJ, Afsharnia K. The comparison of emotional intelligence and hardiness in addicts and non-addicts. Arab J Business Manag Rev. 2014;3(7):196.

21. Besharat MA. Reliability and factorial validity of a Farsi version of the 20-item Toronto Alexithymia Scale with a sample of Iranian students. Psychol Rep. 2007;101(1):209-20. doi: 10.2466/ pro.101.1.209-220. [PubMed:17958129]

22. Bayrami M, Esmaili A. The comparison of factors and personality traits in sexually high risk and non high risk students.Urmia Med J. 2010;21(3):215-20.

23. Bagherian R, Ahmadzadeh G, Yazdani E. Study of coping styles among dialysis patients. Koomesh. 2009;10(2):Pe111-7.

24. Folkman S, Lazarus RS. An analysis of coping in a middleaged community sample. J Health Soc Behav. 1980;21(3):219-39. [PubMed: 7410799]

25. Sirgy MJ. The psychology of quality of life: Hedonic well-being, life satisfaction, and eudaimonia:Virginia: Springer; 2012.
26. Currie C. Social determinants of health and well-being amongyoung people. World Health Organization Regional Office for Europe Copenhagen; 2012. Available from: http://www.euro.who.int/__ data/assets/pdf_file/0003/163857/Social-determinants-of-healthand-well-being-among-young-people.pdf.

27. Proctor C, Maltby J, Linley PA. Strengths Use as a Predictor of Well-Being and Health-Related Quality of Life. J Happiness Stud. 2010;12(1):153-69. doi: 10.1007/s10902-009-9181-2.

28. Maestas KL, Sander AM, Clark AN, van Veldhoven LM, Struchen MA, Sherer M, et al. Preinjury coping, emotional functioning, and quality of life following uncomplicated and complicated mild traumatic brain injury. J Head Trauma Rehabil. 2014;29(5):407-17. [PubMed: 23535388]

29. Prati G, Pietrantoni L, Cicognani E. Coping strategies and collective efficacy as mediators between stress appraisal and quality of life among rescue workers. Int J Stress Manag. 2011;18(2):181-95. doi:10.1037/a0021298.

30. Cappe E, Wolff M, Bobet R, Adrien JL. Quality of life: a key variable to consider in the evaluation of adjustment in parents of children with autism spectrum disorders and in the development of relevant support and assistance programmes. Qual Life Res. 2011;20(8):1279-94. doi:10.1007/s11136-011-9861-3. [PubMed: 21312064]

31. Kohli R, Sane S, Ghate M, Paranjape R. Coping strategies of HIV positive individuals and its correlation with quality of life in Pune, India. Int Soc Work. 2014:0020872813519658.

32. Graven LJ, Grant JS. Coping and health-related quality of life in individuals with heart failure: An integrative review. Heart $\mathcal{E}$ Lung: The Journal of Acute and Critical Care. 2013;42(3):183-94. doi: 10.1016/j.hrtlng.2012.12.002. [PubMed:23312147]

33. Poelmans S, Stepanova O, Masuda A. Handbook of Work-Family Integration: Research, Theory, and Best Practices. Academic Press; 2011.

34. Walker R, Stephens RS. Protective behavioral strategies mediate problem-focused coping and alcohol use in college students. Addict Behav. 2014;39(6):1033-7. doi: 10.1016/j.addbeh.2014.02.006. [PubMed: 24629479]

35. Hudson TM. Impact of stress-coping strategies on perceived stress, intrinsic motivation, and self-efficacy levels of students. GardnerWebb University; 2013. 